\title{
Transurethral excision and re-erosion of mesh material after transobturator tape surgery: A case report
}

\author{
(1) Sener Gezer, ${ }^{1}$ (1) Harun Levent Gulculer ${ }^{2}$ \\ 1Division of Gynecologic Oncology, Department of Obstetrics and Gynecology, Kocaeli University Faculty of Medicine, Kocaeli, Turkey \\ ${ }^{2}$ Department of Obstetrics and Gynecology, Kanuni Sultan Suleyman Training and Research Hospital, Istanbul, Turkey
}

\begin{abstract}
Bladder injury is a rare complication of transobturator tape surgery. Herein, we present a female case in whom intravesical mesh was excised using transurethral endoscopic scissors, and another floating mesh material with calculi formation was seen in bladder and excised with endoscopic forceps 2 months later.
\end{abstract}

Keywords: Bladder injury; erosion; transobturator tape; vesical stone.

Cite this article as: Gezer S, Gulculer HL. Transurethral excision and re-erosion of mesh material after transobturator tape surgery: A case report. North Clin Istanb 2019;6(1):89-92.

Slem tress urinary incontinence is a serious health problem which can affect many women and quality of life of the patients. In recent years, minimally invasive surgical techniques have been used increasingly for the treatment of stress urinary incontinence. Although it is less frequent than retropubic incontinence surgery, transobturator tape (TOT) may also lead to bladder injury [1]. Mesh material may erode and can be seen as a vesical stone. Open surgery or endoscopic treatment modalities are possible treatment options for the excision of intravesical mesh.

Herein, we represent a female case in whom intravesical mesh was excised using transurethral endoscopic scissors, and another floating mesh material with calculi formation was seen in bladder and excised with endoscopic forceps 2 months later.

\section{CASE REPORT}

A 30-year-old, gravida 3, parity 3 woman was referred to our hospital with pelvic pain and dysuria. She had underwent TOT operation 1 month before, in another hospital with an indication of stress urinary incontinence. Cystoscopy was performed under local anesthesia and a mesh material was seen on the right side between the 9 oclock and 11 oclock positions in the bladder. We planned mesh excision through the vaginal route; however, we were unable to reach the mesh material. Under the vision of a $30^{\circ}$ cystoscopy, we cut the mesh material in $2 \mathrm{~cm}$ length with scissors from the deeper part of the near bladder mucosa. There was no leakage after filling the bladder with $250 \mathrm{ml}$ methylene blue. An 18F Foley catheter was inserted and left in place for 7 days.

After discharge, the patient suffered from dysuria, and we performed another cystoscopy procedure under local

\section{Received: August 16, 2017 Accepted: February 09, 2018 Online: August 07, 2018}




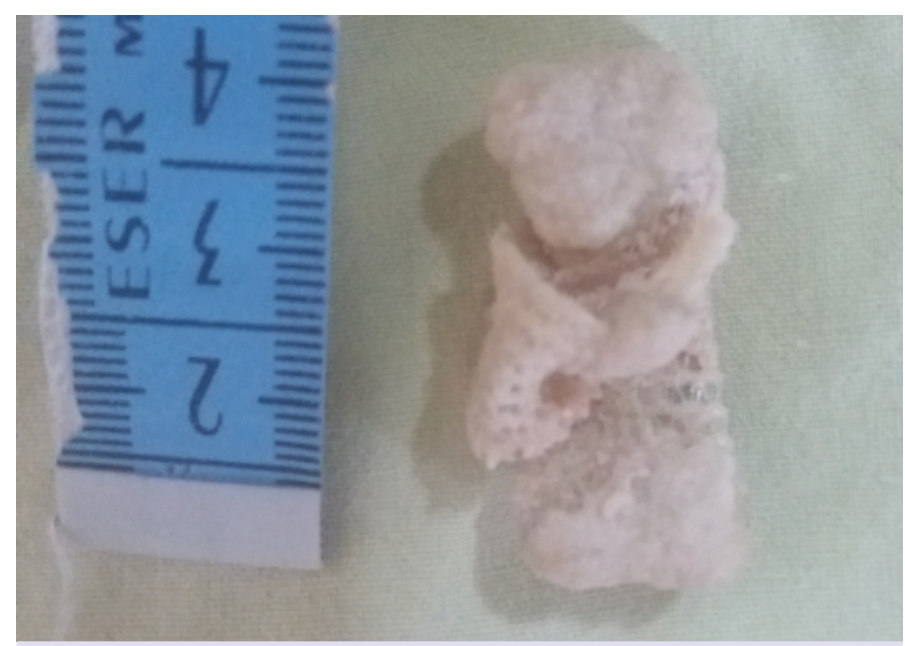

FIGURE 1. Calculi formation in the mesh material.

anesthesia 2 months after cystoscopic mesh excision and 3 months after the first TOT operation. Mucosal healing was achieved at 9 oclock and 11 oclock positions in the bladder; however, a $3 \mathrm{~cm} \times 1.5 \mathrm{~cm}$ floating vesical stone was seen in the bladder. This mass was removed using endoscopic forceps. Naked-eye visual and pathological examination showed calculi formation in the mesh material (Fig. 1).

\section{DISCUSSION}

Although rare, urinary tract injury can be seen following TOT surgery [2-5]. Controversially, some authors report no urinary tract injury following TOT [6-9]. Roumeguere et al. [10] reported one bladder injury after 120 TOT operations. Abdel-Fattah et al. [11] compared outside-in and inside-out techniques among 389 women and found two urethra and two bladder injuries in the outside-in group. Concomitant gynecological operation was performed in three of four cases. In addition, Novara et al. [12] found both bladder and urinary tract injuries to be lower after TOT, compared to tension-free vaginal tape (TVT) in their meta-analysis of controlled randomized trials. Recently, Sun et al. [13] randomized 2.646 women to TOT, TVT-obturator (TVT-O), and TVT groups and found that bladder perforation risk was lower in the TOT (odds ratio [OR] 0.17, 95\% confidence interval [CI] 0.06-0.49) and TVT-O groups (OR 0.18, 95\% CI 0.08-0.38) than the TVT group. However, the authors reported that three bladder perforations were diagnosed in routine cystoscopy, and the true perforation rate could be higher than estimated.
In a recent Cochrane meta-analysis, the authors found a significantly lower bladder injury risk in TOT group than retropubic group (RR $0.13,95 \%$ CI $0.08-0.20)$, although they were unable to find significant differences between TOT and TVT-O groups (relative risk [RR] 0.38, 95\% CI: 0.07-1.92) [1]. Furthermore, there was no significant difference between monoflament and multiflament mesh materials for bladder perforation (monofilament $4.49 \%$ and multifilament $3.67 \%$ [RR $1.15,95 \%$ CIः 0.49-2.70]).

Excision of mesh materials from bladder can be done by cystoscopy or endoscopy. Johnson et al. [14] used scissors from suprapubic route for cutting sling material after holmium laser lithotripsy in six patients who have vesical stone formation. Oh and Ryu [15] performed transurethral resection (TUR) to excise mesh material in 14 patients, six of them had bladder stone formation, and cystolithotripsy was performed before TUR. Jo et al. [16] also reported 20 intravesical and three intraurethral mesh excision procedures, of which 16 were done by TUR with an electrode loop and seven by holmium laser. Concurrently, vesicovaginal fistulas developed in two patients, remnant mesh was in five patients, and TUR-reoperation was performed in one patient. One patient with remnant mesh also developed recurrent stress urinary incontinence in the holmium group. Doumouchtsis et al. [17] used holmium laser for excision of mesh and reported recurrent erosion in four of six patients, which could be the result of a sharp incision of the mesh at the entrance and exit points. In our case, these sharp ends could be the main factor for re-erosion and protrusion of remnant mesh into the bladder. Frenkl et al. [18] described an algorithm for 22 patients and suggested cystography due to the challenges during endoscopic excision (calculi formation and inadequate tension of mesh). Baracat et al. [19] and Jorion [20] also performed laparoscopic suprapubic trocar to immobilize mesh while cutting it through the transurethral route.

In case of difficulty in separating the mesh from bladder, partial cystectomy may be an alternative. Deng et al. [21] reported one urethral diverticulum and three urethravaginal fistulas in 22 perforated bladders. Mclennan [22] applied hysteroscopic scissors to avoid diathermy. Similarly, Irer et al. [23] used scissors and forceps for the mesh excision. In another study, Foley et al. [24] performed TUR in six patients, and one of them needed reoperation with TUR, while two patients required open surgery. The author used illuminated nasal speculum while cutting three urethral meshes with scissors. Pneu- 
matic lithotripsy can be used preoperatively if the bladder stone is large. [25]

Bladder perforation can be diagnosed based on the leakage of urine at the time of injury from trocar insertion site. Methylene blue is an alternative method which can be performed before cystoscopy. A $70^{\circ}$ optic should be used to assess the bladder neck and urethra during cystoscopy. There is no need to repair bladder injury which is intraoperatively diagnosed, since it does not cause long-term sequelae, and bladder catheterization for 3-7 days is often sufficient. Hematuria, recurrent urinary tract infections, and peritonitis during the postoperative period are the major symptoms for perforation and need further evaluation.

The use of index finger to push the bladder neck medial can be also helpful to avoid bladder perforation during TOT surgery. Bladder should be empty during trocar placement. Cystoscopy can be used at the beginning of surgeon's learning curve. There is a limited number of evidence suggesting which patients need cystoscopy following TOT surgery; however, in some cases such as recurrent surgery, difficulties in the insertion of trocar are optimal indications for cystoscopy.

It is still controversial which technique should be used for the excision of mesh material from bladder. It often depends on the surgeon's experience and availability of technical equipment. If it is possible, removal of the whole mesh material by the transvaginal route may prevent these mesh complications. In our case following TOT surgery, we excised the mesh material from bladder mucosa with sharp scissors, and probably due to the sharp end, the mesh material at the outside of bladder was protruded into the bladder and formed the vesical stone. Since holmium laser can create sharp points such as sharp scissors, electrode loop excision can be a safer method to avoid similar complications. Although pneumatic or laser lithotripsy could be used to break the vesical stone, we removed the mesh with cystoscopic forceps as one single part.

Informed Consent: Written informed consent was obtained from the patient for the publication of the case report and the accompanying images.

Conflict of Interest: No conflict of interest was declared by the authors.

Financial Disclosure: The authors declared that this study has received no financial support.

Authorship Contributions: Concept - S.G.; Design - S.G.; Supervision - S.G.; Materials - H.L.G.; Data collection \&/or processing -
H.L.G.; Analysis and/or interpretation - S.G., H.L.G.; Writing - S.G., H.L.G.; Critical review - S.G., H.L.G.

\section{REFERENCES}

1. Ford AA, Rogerson L, Cody JD, Ogah J. Mid-urethral sling operations for stress urinary incontinence in women. Cochrane Database Syst Rev 2015;7:CD006375. [CrossRef]

2. Hermieu JF, Messas A, Delmas V, Ravery V, Dumonceau O, BocconGibod L, et al. Bladder injury after TVT transobturator. Prog Urol 2003;13:115-7.

3. Minaglia S, Ozel B, Klutke C, Ballard C, Klutke J. Bladder injury during transobturator sling. Urology 2004;64:376-7. [CrossRef]

4. Cindolo L, Salzano L, Rota G, Bellini S, D'Afiero A. Tension-free transobturator approach for female stress urinary incontinence. Minerva Urol Nefrol 2004;56:89-98.

5. Smith PP, Appell RA. Transobturator tape, bladder perforation, and paravaginal defect: A case report. Int Urogynecol J Pelvic Floor Dysfunct 2007;18:99-101. [CrossRef]

6. de Leval J, Waltregny D. New surgical technique for treatment of stress urinary incontinence TVT-obturator: New developments and results. Surg Technol Int 2005;14:212-21.

7. Waltregny D, Reul O, Mathantu B, Gaspar Y, Bonnet P, de Leval J. Inside out transobturator vaginal tape for the treatment of female stres urinary incontinence: interim results of a prospective study after a 1year minimum follow-up. J Urol 2006;175:2191-5. [CrossRef]

8. Lim JL, Quinlan DJ. Safety of a new transobturator suburethral synthetic sling (TVT-O) procedure during the training phase. J Obstet Gynaecol Can 2006;28:214-7. [CrossRef]

9. Neuman M. TVT and TVT-obturator: Comparison of two operative procedures. Eur J Obstet Gynecol Reprod Biol 2007;131:89-92.

10. Roumeguere T, Quackels T, Bollens R, de Groote A, Zlotta A, Bossche $\mathrm{VM}$, Schulman C. Transobturator vaginal tape for female stres incontinence: One year follow up in 120 women. Eur Urol 2005;48:805-9.

11. Abdel-Fattah M, Ramsay I, Pringle S. Lower urinary tract injuries after transobturator tape insertion by different routes: A large retrospective study. BJOG 2006;113:1377-81. [CrossRef]

12. Novara G, Galfano A, Boscolo-Berto R, Secco S, Cavalleri S, Ficarra V, et al. Complication rates of tension-free midurethral slings in the treatment of female stress urinary incontinence: A systematic review and meta-analysis of randomized controlled trials comparing tension-free midurethral tapes to other surgical procedures and different devices. Eur Urol 2008;53:288-308. [CrossRef]

13. Sun X, Yang Q, Sun F, Shi Q. Comparison between the retropubic and transobturator approaches in the treatment of female stress urinary incontinence: A systematic review and meta-analysis of effectiveness and complications. Int Braz J Urol 2015;41:220-9. [CrossRef]

14. Johnson MH, Ferguson GG, Klutke CG. Antegrade endoscopic removal of retained urethral sling mesh in the bladder. J Endourol 2012;26:980-2. [CrossRef]

15. Oh TH, Ryu DS. Transurethral resection of intravesical mesh after midurethral sling procedures. J Endourol 2009;23:1333-7. [CrossRef]

16. Jo DJ, Lee YS, Oh TH, Ryu DS, Kwak KW. Outcomes of transurethral removal of intravesical or intraurethral mesh following midurethral sling surgery. Korean J Urol 2011;52:829-34. [CrossRef]

17. Doumouchtsis SK, Lee FY, Bramwell D, Fynes MM. Evaluation of holmium laser for managing mesh/suture complications of continence surgery. BJU Int 2011;108:1472-8. [CrossRef] 
18. Frenkl TL, Rackley RR, Vasavada SP, Goldman HB. Management of iatrogenic foreign bodies of the bladder and urethra following pelvic floor surgery. Neurourol Urodyn 2008;27:491-5. [CrossRef]

19. Baracat F, Mitre AI, Kanashiro H, Montellato NI. Endoscopic treatment of vesical and urethral perforations after tension-free vaginal tape (TVT) procedure for female stress urinary incontinence. Clinics (Sao Paulo) 2005;60:397-400. [CrossRef]

20. Jorion JL. Endoscopic treatment of bladder perforation after tensionfree vaginal tape procedure. J Urol 2002;168:197. [CrossRef]

21. Deng DY, Rutman M, Raz S, Rodriguez LV. Presentation and management of major complications of midurethral slings: Are complications under-reported? Neurourol Urodyn 2007;26:46-52. [CrossRef]

22. McLennan MT. Transurethral resection of transvaginal tape. Int Urogynecol J Pelvic Floor Dysfunct 2004;15:360-2.

23. Irer B, Aslan G, Cimen S, Bozkurt O, Celebi I. Development of vesical calculi following tension-free vaginal tape procedure. Int Urogynecol J Pelvic Floor Dysfunct 2005;16:245-6. [CrossRef]

24. Foley C, Patki P, Boustead G. Unrecognized bladder perforation with mid-urethral slings. BJU Int 2010;106:1514-8. [CrossRef]

25. Mustafa M, Wadie BS. Bladder erosion of tension-free vaginal tape presented as vesical stone; management and review of literature. Int Urol Nephrol 2007;39:453-5. [CrossRef] 